\title{
Hydroxychloride Trace Minerals Have a Positive Effect on Growth Performance, Carcass Quality and Impact Ileal and Cecal Microbiota in Broiler Chickens
}

Sandra J.A. van Kuijk ( $\sim$ sandra.van.kuijk@trouwnutrition.com )

Trouw Nutrition

Yanming Han

Trouw Nutrition

Ana Isabel Garcia-Ruiz

Trouw Nutrition

Ana Rodiles

Trouw Nutrition

\section{Research}

Keywords: Hydroxychloride trace minerals, broiler chickens, growth performance, gut microbiota

Posted Date: August 28th, 2020

DOI: https://doi.org/10.21203/rs.3.rs-65394/v1

License: (9) This work is licensed under a Creative Commons Attribution 4.0 International License. Read Full License

Version of Record: A version of this preprint was published on March 9th, 2021. See the published version at https://doi.org/10.1186/s40104-021-00553-7. 


\section{Abstract}

Background: The objective was to study the effect of hydroxychloride trace minerals (HTM) on growth performance, carcass quality and gut microbiota of broiler chickens in comparison to sulphate trace minerals (STM). In total 1440 male Ross 308 day-old chicks were divided over 12 replicate pens with 30 birds each per treatment. Four different treatments were tested according to a $2 \times 2$ factorial study design, where the animals received a three phase diet containing either inorganic $\mathrm{Zn}$ from sulphates or Zn from HTM in high (80 ppm Zn) or low Zn dosage (20 ppm Zn). In all treatments 15 ppm Cu was added from the same mineral source as the $\mathrm{Zn}$. Body weight and feed intake were measured on day 0, 10, 27 and 34, while carcass and breast meat yields were measured at the end of the study (day 34). In addition, high-throughput sequencing analysis was performed in digesta samples from ileum and cecum to study the gut microbiome (day 34 ).

Results: The results showed an improved $(P<0.05)$ body weight of broiler chickens fed HTM, regardless of $Z n$ level, on day 27 , while on day 34 this effect remained as a tendency $(P=0.0542)$. In the overall study period, birds fed HTM had a higher $(P<0.05)$ average daily gain and average daily feed intake when compared to birds fed STM. The mineral source did not affect the carcass characteristics, however, feeding $80 \mathrm{ppm}$ Zn resulted in a significantly higher $(\mathrm{P}=0.0171)$ breast meat yield, regardless of source. High-throughput sequencing analysis of the microbiota revealed a higher microbial diversity in the ileum and cecum of HTM fed birds compared to STM fed birds. Taxonomical differences were mainly found in the cecum, specifically between the group fed high and low Zn levels from HTM. This is in line with the mineral contents observed in the cecal digesta. Comparing both groups fed 80 ppm Zn, the HTM group had more Streptococcaceae, Streptococcus, Clostridia, Weissella and Leuconostocaceae compared to the STM group.

Conclusions: HTM improved growth performance of the birds; and the source and level of Zn modulated the gut microbiota communities in broilers differentially.

\section{Background}

Zinc is an essential trace mineral for broiler chickens. Zinc has been proven to play a role in immunity, enzymatic processes and eventually in growth (Salim et al., 2008; Prasad, 2009). Therefore, Zn deficiency can cause major problems. To prevent a deficiency, it is commercial practice to add Zn to diets at higher dosages than those advised for poultry by the National Research Council (NRC) (National Research Council, 1994). Higher dosages in the diet will also result in more excretion of this trace mineral into the environment. Recently, the EFSA (European food safety agency) published guidelines about the importance to reduce the amount of heavy metals into the environment (EFSA, 2014). Thus, it is essential to reduce the amount of $\mathrm{Zn}$ added to broiler diets. As expected, reducing the dose in the diet will reduce the excretion into the environment (Bao et al., 2007). Inorganic trace minerals in the form of sulphates have a lower bioavailability than other commercially available mineral sources (Wedekind et al., 1992). Hydroxychloride trace minerals (HTM) are a good example of a more bioavailable mineral source in broilers compared to sulphate trace minerals (STM) (Batal et al, 2001). In addition, HTM do have a unique crystalline structure that is not readily soluble at a pH above 4 (Miles et al., 1998). Moreover, HTM are much less reactive in the feed than STM, and do not interact with antinutritional factors such as phytate (Luo et al., 2005; Lu et al., 2010). In addition, the low solubility at higher $\mathrm{pH}$ suggests that the $\mathrm{pH}$ in the gastrointestinal tract may have a specific effect on the function of HTM. Both differences in solubility and reactivity between HTM and STM may result in different quantities and forms of $\mathrm{Zn}$ present in the different compartments of the gastrointestinal tract. It is also known that $\mathrm{Zn}$ is essential for several microbes (Gielda and DiRita, 2012), indicating that a different source and level of Zn available in the gut may influence the microbiota. Olukosi et al. (2018) already showed a beneficial effect of HTM on growth performance and carcass quality in broiler chickens. The objective of the present study was to investigate the effects on growth performance, carcass and breast meat yield, and microbiota of broiler chickens fed STM or HTM in high and low Zn dosages. With the above mentioned differences in solubility and bioavailability, we expected a larger contrast between high and low Zn levels in HTM fed birds compared to STM fed birds. 


\section{Materials And Methods}

\section{Animals and dietary treatments}

In total, 1440 newly hatched male Ross 308 broiler chicks were housed at the Poultry Research Facility of Trouw Nutrition, Casarrubios del Monte, Spain. The birds were randomly allocated into groups of 30 animals per floor pen $\left(3 \times 1 \mathrm{~m}^{2}\right)$ with 6 and $18 \mathrm{~h}$ of light/dark periods. Each pen provided $0.10 \mathrm{~m}^{2} /$ bird with wood shavings litter. Each group was randomly allocated to one of four treatments with 12 replicate pens each. The four treatments were applied according to a $2 \times 2$ factorial study design, in which two mineral sources of zinc (sulphate STM and hydroxychloride HTM) were tested at two different zinc levels (high: 80 ppm and low: 20 ppm), whereas to all diets 15 ppm Cu was added from the same mineral source as the Zn. Sulphate trace minerals source were added to the feed in the form of Zn sulphate (Zinc sulphate monohydrate, Sigma-Aldrich, Saint Louis, MO, USA), and Cu sulphate (Copper(II) sulphate pentahydrate, Sigma-Aldrich, Saint Louis, MO, USA). Hydroxychloride trace minerals were added at the same Zn (IntelliBond Z, Trouw Nutrition, The Netherlands) and Cu (IntelliBond C, Trouw Nutrition, The Netherlands) levels as for the sulphate minerals. The composition of the diets is shown in Table 1. The wheat-soybean meal diets were offered as pellets in three phases, with phase 1 being from day 0 to 10, phase 2 from day 10 to 27 and phase 3 from day 27 to 34, according to the NRC requirements of the species (National Research Council, 1994). The analysed mineral contents of the diets are shown in Table 2. Animals were fed ad libitum throughout the entire study period of 34 days.

At the end of the experiment, 6 animals per pen were selected based on average body weight and euthanized by cervical dislocation according to the guidelines of the Ethics Committee of Poultry Research Centre of Trouw Nutrition for the humane care and use of animals in research. Animal procedures were verified by the External Ethical Committee of "Hospital General Universitario de Ciudad Real", and approved by the Junta de Castilla-La Mancha Animal Welfare department as compliable with the RD 53/2013 of the 1st of February which establishes basic rules applied to protect animals used for research, and other scientific matters like teaching. The regulations conform to the European Directive 2010/63/EU for the Protection of Vertebrate Animals Used for Experimental and Other Scientific Purposes (Brussels, European Union) and achieve the standard of care required by the US Department of Health and Human Services' Guide for the Care and Use of Laboratory Animals. Five animals were used for carcass and breast meat yields and the remaining animal was used for microbiota and mineral content. Samples were collected aseptically by opening the abdominal cavity with a sterile blade, the intestinal content (digesta) from the ileum and cecum was placed into a sterile tube until further analysis. All samples were immediately snap frozen on dry ice and then transferred to a $-80^{\circ} \mathrm{C}$ freezer.

\section{Zootechnical parameters}

Body weight and feed intake was measured on pen level at the start of the experiment at day 0 and at the end of each feeding phase at day 10, 27 and 34. The body weight and feed intake measures were used to calculated the average daily gain, the average daily feed intake and the feed conversion ratio (feed:gain). On day 34, carcass and breast meat weight were used to calculate carcass and breast yield, as the percentage of the live weight or the carcass weight, respectively.

\section{Mineral content of ileum and cecum digesta}

Zinc and copper content in the diets and in 12 digesta samples from ileum and 12 digesta from ceacum per treatment (from the same animal) were analysed according to ISO (ANA-00281) using inductively coupled plasma-mass spectroscopy (ICPMS) (Nexion 300D, Perkin elmer, Waltham, MA, USA) with an autosampler coupled (4DX, Elemental Scientific (ESI), Omaha, NE, USA). The chemicals used were nitric acid (67-69\%) and hydrochloric acid (34-35\%) of ultra pure grade for trace mineral analysis (VWR, Amsterdam, Netherlands).

\section{DNA extraction, PCR and library preparation}


From the ileal and cecal digesta $200 \mathrm{mg}$ of samples were lysated with MagNA Lyser (Roche, Burges Hill, UK) previously to DNA extraction. DNA extraction was performed with PowerMicrobiome ${ }^{T M}$ RNA isolation kit (MO BIO, Carlsbad, CA, USA) following the manufacturer's instructions with some modifications, such as omitting the $\beta$-mercaptoethanol and DNase I steps. The concentration of the extracted prokaryotic DNA in each sample was calculated by qPCR with 926F (De Gregoris et al., 2011) and 1027R (Claesson et al., 2009) primers at a concentration of 0.4 $\mu \mathrm{M}$ in iQ SYBRgreen Supermix qPCR (BioRad Laboratories Inc., Hercules, CA, USA). PCR was carried out with Universal primers 341F-785R of V3-V4 regions to amplify 16S rRNA in a dual-index sequencing strategy according to Kozich et al. (2013) with Taq KAPA HiFi Hotstart ReadyMix (Kapa Biosystems, Woburn, MA, USA) and $12.5 \mathrm{ng}$ bacterial DNA to reduce PCR bias. Four PCR products from the same sample were pooled before cleaning up step with QIAquick Gel Extraction Kit (Qiagen, Hilden, Germany). Negative controls and MOCK communities were PCR and included in the sequencing. The library was sequenced on an Illumina HiSeq platform $2 \times 300$ paired end. All reagents used were molecular grade.

\section{High-throughput sequencing and bioinformatics analysis}

Raw fastq files were imported, demultiplexed and processed using QIIME 2 (version 2018.6) (Bolyen et al., 2019). Pairedends fastq files were quality filtered and dereplicated with dada2 (Callahan et al., 2016). Taxonomy was assigned to the resulting 16s RNA marker genes against the SILVA version 132 99\% OTUs (trained with naive-bayes for 341F-785R region of the 16S) using sklearn classifier method to determine the taxonomy according to Bokulich et al. (2018). Chloroplast and mitochondria were considered as contamination and removed from the otus_biom table, as well as low frequency OTUs ( $<10$ reads in $<5$ samples), previously to statistical analysis. Alpha and beta diversity were calculated under rooted phylogeny downsampling to the lowest count of sequences.

\section{Statistical analysis}

The pen was the experimental unit for all parameters. Growth performance data were analysed according to the $2 \times 2$ factorial design using the MIXED procedure in SAS software (SAS Institute Inc. Cary, NC, 2012). The model included source and level and feeding phase as fixed effects. The different time points were included as repeated measures. The carcass and breast meat yield were subjected to the GLIMMIX procedure in SAS. Post hoc analysis was done using Tukey. R in QIIME2 (version 2018.6) was used to analyse alpha diversity with Kruskal-Wallis and Spearman for correlations, beta diversity with PERMANOVA and ANOSIM with a sequencing depth of 234,000 and 175,000 sequences for ileum and cecum, respectively. Taxonomy data was analysed with LEfSE (Segata et al., 2011) and represented in RDA plots with Canoco. Microbiota results were analysed comparing the four treatments, and in addition the main effects of mineral source and level were explored. The results were considered being significantly different when $\mathrm{P}<0.05$.

\section{Results}

\section{Growth performance and carcass characteristics}

Growth performance results are shown in Table 3. At day 27 of the study, birds fed HTM had a significantly $(P=0.0229)$ higher body weight than birds fed STM, regardless of mineral levels. This continued until day 34 as a strong trend $(P=0.0542)$ towards an increased body weight in birds fed HTM compared to birds fed STM. Average daily gain (ADG) and average daily feed intake (ADFI) followed the same patterns as body weight throughout the study. In this case, between 10 and 27 days a tendency was observed towards an increased ADG $(P=0.0738)$ and ADFI $(P=0.0846)$ for birds fed HTM compared to birds fed STM. However, this tendency resulted in a significantly improved ADG $(P=0.0130)$ and ADFI $(P=0.0125)$ over the entire period for HTM fed birds compared to STM fed birds, regardless of mineral level. As a result, the feed conversion ratio (FCR) was not significantly different among treatments.

The effect of the treatments on carcass and breast meat yield were measured at the end of the study (Table 4). No significant differences were found in carcass yield. Breast meat yield was significantly higher in birds fed 80 ppm Zn 
compared to birds fed 20 ppm Zn ( $\mathrm{P}=0.0171)$, while no significant differences were found between the sources or any sourcexlevel interaction.

\section{Mineral content in ileal and cecal digesta}

The mineral content in the digesta from ileum and cecum is shown in Table 5. Birds fed HTM had significantly higher Cu contents in the ileum compared to the birds fed STM $(P=0.004)$. The $\mathrm{Zn}$ content in the ileum was proportional to the dietary Zn level, where birds fed a high dietary Zn presented significantly higher Zn than in birds fed low Zn $(P<0.0001)$. In the cecum, the Cu level remained similar across the treatments, while $\mathrm{Zn}$ content depended significantly on the supplemented levels $(P<0.0001)$. Surprisingly, there was a significant sourcexlevel interaction where birds fed 80 and 20 ppm Zn from HTM showed the highest and the lowest cecum values, respectively $(P=0.0472)$.

\section{Microbiota}

In total, 42,854,714 sequences were obtained after removal of chloroplast and mitochondria reads (6046 sequences). Rarefactions curves of observed OTUs showed a plateau (Figure 1) and good coverage values close to 1 from 20,000 sequences $(0.9999 \pm 0.0001)$, showing that sampling depth for all the members of the microbial communities were sampled. Alpha and beta diversity showed a clear (and significant) separation between the ileum and cecum.

In the ileum, 23,998,507 sequences were recovered (521,707 $\pm 174,002$ sequences) representing 100 OTUs. Beta diversity ordination represented by redundancy analysis (Figure 1) showed significant distances on ANOSIM $(P=0.020)$ and PERMANOVA $(P=0.014)$ of unweighted unifrac and a trend in jaccard $(P=0.080)$, between microbial communities in the ileum of birds fed 80 ppm Zn from HTM to birds fed 20 ppm from HTM. The STM fed birds showed intermediate values not differing from any of the other treatments tested. The number of observed OTUs of alpha diversity was significantly higher in the group fed 80 ppm Zn from HTM (50 \pm 14.1$)$ than 20 ppm Zn from HTM (39 \pm 8.3$)(P=0.049)$, as well as the phylogenetic distances, whereas both STM groups were in-between (Table 6). In addition, Spearman correlations showed a tendency towards a positive correlation between the number of observed species in the ileum and the breast meat yield $(P=0.093)$ (data not shown). The taxonomy at phyla level (data not shown) showed Firmicutes as main phyla ( $99.8 \%$ ), followed by Actinobacteria $(0.15 \%)$, Proteobacteria $(0.08 \%)$ and Patescibacteria $(0.01 \%)$. Actinobacteria phyla was significantly higher in group fed 80 ppm Zn from HTM (0.34\%) in comparison with the group fed 20 ppm Zn from HTM (0.03\%) (P=0.043). At genus level, the main organism present in the ileum was Lactobacillus (>88\%) (Table 7).

Differences in the remaining genera in the ileum are shown in Table 7 and visualized in Figure 2 . The different areas show that the diet containing 80 ppm Zn from HTM permitted some diversity strength in the ileum at day 34. The arrows in Figure 2 show significantly increased Enterococcus $(\mathrm{P}=0.012)$ and Streptococcus $(\mathrm{P}=0.042)$, in comparison to the diet containing 20 ppm Zn from STM, which in turn presented higher Lactobacillus than 80 ppm Zn from HTM ( $P=0.010)$. The group fed 80 ppm Zn from HTM also presented higher Bifidobacterium $(\mathrm{P}=0.018)$, Blautia $(\mathrm{P}=0.034)$, Streptococcus $(\mathrm{P}=0.043)$, Weissella $(\mathrm{P}=0.039)$, Eubacterium hallii group $(\mathrm{P}=0.033)$, Ruminococcus torques $g(\mathrm{P}=0.043)$ than the group fed $20 \mathrm{ppm} \mathrm{Zn}$ from HTM (Table 7). Dosage levels (20 versus $80 \mathrm{ppm}$ ) presented significant differences of abundance in Lactobacillus (20 ppm) and in Streptococcus and Enterococcus (80 ppm), mainly because of the high influence of the group fed $80 \mathrm{ppm}$ Zn from HTM. No significant difference was found by the overall source effect, regardless of Zn level.

In the cecum, $17,250,171$ sequences were recovered (359,379 $\pm 111,998$ sequences) representing 644 OTUs. Beta diversity ordination represented by redundancy analysis (Figure 2) showed significant distances in ANOSIM per source of the unweighted unifrac and jaccard distances $(P=0.019$ and $P=0.027$, respectively), promoted by significant differences between both groups fed 20 ppm Zn ( $P=0.007$ and $P=0.031$, respectively). Feeding 20 ppm Zn from HTM also presented marked differences in the ANOSIM and PERMANOVA of unweighted unifrac distances in comparison with feeding $80 \mathrm{ppm} \mathrm{Zn}$ from $\operatorname{HTM}(P=0.014$ and $P=0.011$, respectively) or from STM $(P=0.011$ and $P=0.022$, respectively). The alpha diversity confirmed the differences found in the ordination of the bacterial communities (see Table 6). The Shannon index, an indication for 
population diversity, shows a tendency towards a higher diversity in the HTM fed groups compared to the STM groups $(P=0.066)$, with the group fed 80 ppm Zn from STM having the lowest diversity in comparison with the group fed 20 ppm Zn from HTM $(P=0.049)$. The observed species in the cecum tended to be higher in birds fed $20 \mathrm{ppm} Z \mathrm{n}$ from HTM compared to the birds fed 80 ppm Zn from STM $(P=0.067)$. The evenness showed a trend towards an increased $(P=0.099)$ richness in the HTM groups compared to the STM groups, regardless of Zn level. Taking the phylogenetic distances into account, the Faith_PD parameter did show a trend towards a different community in the groups fed $20 \mathrm{ppm}$ Zn compared to the groups fed 80 ppm Zn ( $P=0.070)$, and specifically between 20 ppm Zn from HTM and 80 ppm Zn from STM (P=0.024) (Table 6). In addition, significant positives correlations were found between the carcass yield and Shannon $(P=0.0322)$, evenness $(P=0.046)$ or observed species (trend, $P=0.062)$ in the cecum. Also the ADFI and ADG performance indexes tended to be positively correlated to the richness or evenness of the microbiota ( $P=0.053$ and $P=0.098$, respectively) (data not shown).

The taxonomy in the cecum presented as the main phylum Firmicutes (87.3\%), Actinobacteria (9.5\%), Bacteroidetes (3.1\%), and in less extend Proteobacteria (0.06\%), Tenericutes $(0.05 \%)$ and Cyanobacteria $(0.01 \%)$. On family level, main species present in the cecum were the Lachnospiraceae, Ruminococcaceae, Lactobacillaceae and Bifidobacteriaceae.

At genus level, the main organisms present in the cecum were Lactobacillus, Faecalibacterium, unknown genus from Lachnospiraceae family, Bifidobacterium, several Ruminococcus groups, Butyricoccus, Blautia and Alistipes (Table 8). Being $80 \mathrm{ppm}$ the most common commercial level used in broiler feed the most interesting comparison would be between groups fed 80 ppm Zn from either STM or HTM. In this case, significant differences were found in Streptococcus and two unidentified genus from the family vadin BB60 being higher in birds fed $80 \mathrm{ppm}$ Zn from HTM than from STM. Only CHKCIOO2 from Eggerthellaceae family presented higher values in birds fed $80 \mathrm{ppm}$ Zn from STM than from HTM. As in the ileum, the majority of the significant differences were in between HTM groups (Table 8). The group fed 20 ppm Zn from HTM contained higher relative abundances of Blautia, Anaerostipes, Christensenellaceae R-7 group, Ruminococcus 1 , Ruminococcaceae UCG-004, Tyzzerella, Eubacterium nodatum group, Ruminococcaceae_uncultured, Family XIII (AD3011 and UCG-001 groups), Eubacterium brachy group, Pygmaiobacter, Peptococcaceae_other, whereas the group fed $80 \mathrm{ppm} \mathrm{Zn}$ from HTM showed significantly higher relative amounts of vadin BB60 group (Table 8). The group fed 20 ppm Zn from STM reached the highest Anaerotruncus level, Tyzzerella 3, Family XIII UCG-001, and Brachybacterium, and the group fed 80 ppm $\mathrm{Zn}$ from STM the highest CHKCIOO2 (Table 8). Dosage level 20 ppm presented higher significant abundance of Anaerostipes, Pygmaiobacter, unknown genus from Peptococcaceae family, Christensenellaceae R-7 group and family XIII in comparison with 80 ppm. This result is mainly cause by the high influence of the HTM20 group. Source (HTM vs STM) also changed the microbial composition of the cecum. In this case, HTM groups had an increased abundance of Streptococcus and Enteroccocaceae family, and STM groups of family vadin BB60 group and unknown genus from Christensenellaceae family.

\section{Discussion}

This study showed a beneficial effect of HTM on growth performance, specifically on body weight and average daily gain. The breast meat yield was not influenced by mineral source, however only by Zn level with higher Zn resulting in a higher breast meat yield. This is in contrast to the differences reported by Olukosi et al. (2018), who described a beneficial effect of HTM over STM and a beneficial effect of 20 ppm over 80 ppm Zn. In that study, the carcass results were in line with the growth performance results, which was not the case in the current study. Olukosi et al. (2018) observed an improved gain:feed in the overall study period in the birds fed HTM compared to STM, regardless of mineral level. In the current study, feeding HTM resulted in a higher gain, but due to the increased feed intake, FCR was not significantly different. The main difference between Olukosi et al. (2018) and the current study could be the presence of non-starch polysaccharide (NSP) degrading enzymes in the current diet, which had a higher wheat content. High wheat diets are often challenging gut health due to the high viscosity (Choct 2006; Munyaka et al., 2016). Adding NSP enzymes to the diet in the current study may have caused a lower viscosity, thus a less challenging condition in the gut. These results suggested that the trace mineral sources tested here could likely behave differently in their physiological effect in the gastro-intestinal tract (GIT). The Zn contents in 
ileal and cecal digesta seemed to confirm this different behaviour by the two mineral sources. The main difference was observed in the cecum between the birds fed either 80 or 20 ppm Zn from HTM. The higher Zn level in the cecum in the birds fed 80 ppm Zn from HTM suggested more available Zn later in the intestine. It is important to have Zn available late in the intestine as the most controlled uptake takes of $\mathrm{Zn}$ takes place in the ileum (Yu et al., 2008). Not only more $\mathrm{Zn}$ is present, HTM are also defined as more bioavailable for the animal compared to STM (Batal et al., 2001). Another important characteristic of HTM is related to their crystalline structure (Hawthorne and Sokolova, 2002). This structure results in a low solubility above $\mathrm{pH} 4$, leading to a more gradual release throughout the gastrointestinal tract. As a result, more minerals are available later in the intestine of HTM-fed birds. This study confirmed that more $\mathrm{Zn}$ was present in the lower part of the gastrointestinal tract when 80 ppm HTM was fed. The absorption of Zn was not measured in this study, so the uptake could not be confirmed. In the 20 ppm Zn groups it may be expected that a body Zn excess may not be reached, resulting in less recirculation of $\mathrm{Zn}$ into the intestine. With a higher bioavailability of HTM, less $Z n$ would be expected in the gut contents in birds fed 20 ppm Zn from HTM compared to 20 ppm Zn from STM. The difference in Zn content of digesta may also explain the differences observed in microbiota analysis.

Generally, the main organism present in the ileum was Lactobacillus. This is in line with the study of Munyaka et al. (2016), who also described Lactobacillus to be the most abundant species in the ileum of birds fed high fiber diets. In the cecum the main species on family level were Lachnospiraceae, Ruminococcaceae, Lactobacillaceae and Bifidobacteriaceae. This is in line with Munyaka et al. (2016), who observed Lachnospiraceae as the main family in the cecum as well as, with Pourabedin and Zhao (2015) review where it was shown that the cecum is mainly colonised by Clostridia with Clostridiaceae, Lachnospiraceae and Ruminococcaceae as main families.

The current study shows indications for an improved richness and evenness in the diversity of cecal microbiota in birds fed HTM. In literature, Zn is described to be important for diversity, since chronic Zn deficiency is related to a reduced species richness and diversity in the cecum (Reed et al., 2015). Moreover, Gielda and Di Rita (2012) and Reed et al. (2015) also revealed the importance of $\mathrm{Zn}$ for a proper microbiota functioning. In the present study, even though $\mathrm{Zn}$ levels were above current recommendations for broiler chickens the source of $\mathrm{Zn}$ also showed an important effect in this sense. The current results suggest that HTM is more available for both the animal, based on the performance results, and for the microbiota, based on the species diversity results.

A difference in microbiota may also be related to the growth performance of broiler chickens. Stanley et al. (2012) showed a different cecal microbial community between high vs. low performing birds in terms of FCR. Although they suggested that cellulose and resistant starch degrading organisms were linked with high performing birds, most species could not be identified. The increase of Blautia, a fiber degrading organism, in ileal digesta of birds fed 80 ppm Zn from HTM may support this hypothesis. It is unknown whether the different other species observed in the current study may be responsible for the difference in growth performance, however the positive correlation of carcass yield and ADF trend with Shannon and evenness indexes could support this fact.

Change in specific species of the microbiota may not always lead to a clear conclusion. For example, Clostridia are commonly found in the cecum of chickens, as shown both in laying hens and broilers (Rehman et al., 2007; Lan et al., 2002). Similarly, Streptococcus species have been found in the cecum of broiler chickens (Rehman et al., 2007), and depending on the species and abundance, these organisms could be beneficial for the birds. An increase in these organisms may be either beneficial or harmful. For some organisms such as Weissella, which was increased in the ileum of birds fed 80 ppm Zn from HTM, it is known that Zn has an promoting effect on it. Vahjen et al. (2010) observed an increase in Weissella in the ileal digesta of pigs fed high levels of $\mathrm{ZnO}$, showing that high $\mathrm{Zn}$ may increase the presence of this bacteria in the intestinal content.

Interestingly, most of the differences were observed between the groups fed 80 or 20 ppm Zn from HTM, whereas the STM groups reached values in between. This might suggest that HTM is able to modulate the gut microbiota in both sections of the intestine studied. 


\section{Conclusions}

Birds fed diets containing $\mathrm{Cu}$ and Zn from HTM performed better than birds fed minerals from STM. In the overall study, the ADG and ADFI were significantly higher in the HTM fed birds. Also a tendency towards an increased body weight was observed in HTM fed birds. This did not result in differences in carcass yield and breast meat yield. The microbial diversity in the ileum and cecum were higher in the HTM fed birds compared to the STM fed birds. Main differences in the bacterial composition were found in the cecum, especially between the group fed 80 ppm Zn from HTM and 20 ppm Zn from HTM. These were the two groups with the highest contrast in $\mathrm{Zn}$ levels in the cecum. Further, the main taxonomical differences found in the cecum were in between the two groups fed 80 ppm Zn, where the HTM group had more Streptococcus and two unidentified genus from vadin BB60 family and less $\mathrm{CHKCIO02}$ from Eggerthellaceae family, than the STM group. Therefore, results from this study show that HTM can clearly modulate the microbiota, increase bacterial diversity in the GIT and potentially increase the growth performance in chickens.

\section{Declarations}

\section{Ethics approval}

Animal procedures were verified by the External Ethical Committee of "Hospital General Universitario de Ciudad Real", and approved by the Junta de Castilla-La Mancha Animal Welfare department as compliable with the RD 53/2013 of the 1st of February which establishes basic rules applied to protect animals used for research, and other scientific matters like teaching. The regulations conform to the European Directive 2010/63/EU for the Protection of Vertebrate Animals Used for Experimental and Other Scientific Purposes (Brussels, European Union) and achieve the standard of care required by the US Department of Health and Human Services' Guide for the Care and Use of Laboratory Animals.

\section{Availability of data and materials}

The datasets used during the current study are available from the corresponding author on reasonable request.

\section{Competing interests}

The authors declare that they have no competing interests

\section{Funding}

No external funding was obtained for this study.

\section{Authors' contributions}

Study set up, execution: SvK, AIGR, YH; Data analysis: SvK, AR; writing, reviewing and editing manuscript: SvK, YH, AIGR, AR. All authors read and approved the final manuscript.

\section{Acknowledgements}

Not applicable

\section{References}

1. Bao YM, Choct M, lji PA, Bruerton K. Effect of organically complexed copper, iron, manganese, and zinc on broiler performance, mineral excretion, and accumulation in tissues. J Appl Poult Res 2007;16:448-55.

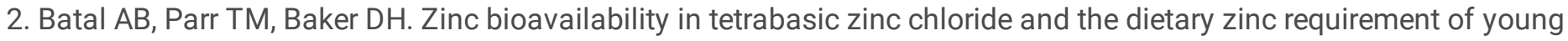
chicks fed a soy concentrate diet. Poult Sci 2001;80:87-90. 
3. Bokulich NA, Kaehler BD, Rideout JR, Dillon M, Bolyen E, Knight R, Huttley GA, Caporaso JG. Optimizing taxonomic classification of marker-gene amplicon sequences with QIIME 2's q2-feature-classifier plugin. Microbiome 2018;17;6(1):90.

4. Bolyen E, Rideout JR, Dillon MR, Bokulich NA, Abnet CC, Al-Ghalith GA, Alexander H, Alm EJ, Arumugam M, Asnicar F, Bai Y, Bisanz JE, Bittinger K, Brejnrod A, Brislawn CJ, Brown CT, Callahan BJ, Caraballo-Rodriguez AM, Chase J, Cope EK, Da Silva R, Diener C, Dorrestein PC, Douglas GM, Durall DM, Duvallet C, Edwardson CF, Ernst M, Estaki M, Fouquier J, Gauglitz JM, Gibbons SM, Gibson DL, Gonzalez A, Gorlick K, Guo J, Hillmann B, Holmes S, Holste H, Huttenhower C, Huttley GA, Janssen S, Jarmush AK, Jiang L, Kaehler BD, Kang KB, Keefe CR, Keim P, Kelley ST, Knights D, Koester I, Kosciolek T, Kreps J, Langille MGI, Lee J, Ley R, Liu YX, Loftfield E, Lozupone C, Maher M, Marotz C, Martin BD, McDonald D, Mclver LJ, Metcalf JL, Morgan SC, Morton JT, Naimey AT, Navas-Molina JA, Nothias LF, Orchanian SB, Pearson T, Peoples SL, Petras D, Preuss ML, Pruesse E, Rasmussen LB, Rivers A, Robeson II MS, Rosenthal P, Segata N, Shaffer M, Shiffer A, Sinha R, Song SJ, Spear JR, Swafford AD, Thompson LR, Torres PJ, Trinh P, Tripathi A, Turnbaugh PJ, Ul-Hasan S, van der Hooft JJJ, Vargas F, Vazquez-Baeza Y, Vogtmann E, von Hippel M, Walters W, Wan Y, Wang M, Warren J, Weber KC, Williamson CHD, Willis AD, Xu ZZ, Zaneveld JR, Zhang Y, Zhu Q, Knight R, Caporaso JG. QIIME 2: Reproducible, interactive, scalable, and extensible microbiome data science. Preprints 2019;27295.

5. Callahan BJ, McMurdie PJ, Rosen MJ, Han AW, Johnson AJA. Holmes SP. DADA2: high-resolution sample inference from Illumina amplicon data. Nat Methods 2016;13:581-3.

6. Claesson MJ, O'Sullivan O, Wang Q, Nikkilä J, Marchesi JR, Smidt H, de Vos WM, Ross RP, O’Toole PW. Comparative analysis of pyrosequencing and a phylogenetic microarray for exploring microbial community structures in the human distal intestine. PLoS One 2009; 4(8):e6669.

7. Choct M. Enzymes for the feed industry: past, present and future. World's Poult Sci J 2006;62:5-16.

8. De Gregoris TB, Aldred N, Clare AS, Burgess JG. Improvement of phylum- and class-specific primers for real-time PCR quantification of bacterial taxa. J of Microbiol Methods Volume 2011;86(3):351-6.

9. EFSA FEEDAP Panel (EFSA Panel on Additives and Products or Substances used in Animal Feed). Scientific opinion on the potential reduction of the currently authorized maximum zinc content in complete feed. EFSA Journal 2014;12(5):3668-745.

10. Gielda LM, DiRita VJ.. Zinc competition among the intestinal microbiota. mBio 2012;3(4):00171-12.

11. Hawthorne FC, Sokolova E. Simonkolleite, $\mathrm{Zn} 5(\mathrm{OH}) 8 \mathrm{Cl} 2(\mathrm{H} 2 \mathrm{O})$, a decorated interrupted-sheet structure of the form [Mழ2]4ᄀ. The Canadian Mineralogist 2002;40:939-946.

12. Kozich JJ, Westcott SL, Baxter NT, Highlander SK, Schloss PD. Development of a dual-index sequencing strategy and curation pipeline for analyzing amplicon sequence data on the MiSeq Illumina sequencing platform. Appl Environ Microbiol 2013;79(17):5112-20.

13. Lan PTN, Hayashi H, Sakamoto M, Benno Y. Phylogenetic analysis of cecal microbiota in chicken by the use of $16 \mathrm{~S}$ rDNA clone libraries. Microbiol Immunol 2002;46(6):371-82.

14. Lu L, Wang RL, Zhang ZJ, Steward FA, Luo X, Liu B. Effect of dietary supplementation with copper sulfate or tribasic copper chloride on the growth performance, liver copper concentrations of broilers fed in floor pens, and stabilities of vitamin E and phytase in feed. Bio Trace Elem Res 2010;138:181-9.

15. Luo XG, Ji F, Lin YX, Steward FA, Lu L, Liu B, Yu SX. Effects of dietary supplementation with copper sulfate or tribasic copper chloride on broiler performance, relative copper bioavailability, and oxidation stability of vitamin $\mathrm{E}$ in feed. Poult Sci 2005;84:888-93.

16. Miles RD, O'Keefe SF, Henry PR, Ammerman CB, Luo XG. The effect of dietary supplementation with copper sulfate or tribasic copper chloride on broiler performance, relative copper bioavailability, and dietary prooxidant activity. Poult Sci 1998;77:416-25.

17. Munyaka PM, Nandha NK, Kiarie E, Nyachoti CM, Khafipour E. Impact of combined $\beta$-glucanase and xylanase enzymes on growth performance, nutrients utilization and gut microbiota in broiler chickens fed corn or wheat-based diets. Poult 
Sci 2016;95:528-40.

18. National Research Council. 1994. Nutrient Requirements of Poultry. 9th rev. ed. Natl. Acad. Press, Washington, DC.

19. Olukosi OA, van Kuijk S, Han Y. Copper and zinc sources and levels of zinc inclusion influence growth performance, tissue trace mineral content, and carcass yield of broiler chickens. Poult Sci 2018;97:3891-8.

20. Pourabedin M, Zhao X. Prebiotics and gut microbiota in chickens. FEMS Microbiol Letters 2015;362.

21. Prasad AS. Zinc: role in immunity, oxidative stress and chronic inflammation. Curr Opin Clin Nutr Metab Care 2009;12:646-52.

22. Reed S, Neuman H, Moscovich S, Glahn RP, Koren O, Tako E. Chronic zinc deficiency alters chick gut microbiota composition and function. Nutrients 2015;7:9768-84.

23. Rehman HU, Vahjen W, Awad WA, Zentek J. Indigenous bacteria and bacterial metabolic products in the gastrointestinal tract of broiler chickens. Archives Anim Nutr 2007;61(5):319-35.

24. Salim HM, Jo C, Lee BD. Zinc in broiler feeding and nutrition. Avian Biol Res 2008;1(1):5-18.

25. Segata N, Izard J, Waldron L, Gevers D, Miropolsky L, Garrett WS, Huttenhower C. Genome Biol 2011; 12(6):R60. Published 2011 Jun 24. doi:10.1186/gb-2011-12-6-r60.

26. Stanley D, Denman SE, Hughes RJ, Geier MS, Crowley TN, Chen H, Haring VR, Moore RJ. Intestinal microbiota associated with differential feed conversion efficiency in chickens. Appl Microbiol Biotechnol 2012;96:1361-9.

27. Vahjen W, Pieper R, Zentek J. Bar-coded pyrosequencing of 16S rRNA gene amplicons reveals changes in ileal porcine bacterial communities due to high dietary zinc intake. Appl Environ Microbiol 2010;76(19):6689-91.

28. Wedekind KJ, Hortin AE, Baker DH. Methodology for assessing zinc bioavailability: efficacy estimates for zincmethionine, zinc sulfate and zinc oxide. J Anim Sci 1992;70:178-87.

29. Yu Y, Lu L, Luo XG, Liu B. Kinetics of zinc absorption by in situ ligated intestinal loops of broilers involved in zinc transporters. Poult Sci 2008;87:1146-55.

\section{Tables}

Table 1 Feed formulation used in the three feeding phases. 


\begin{tabular}{|c|c|c|c|}
\hline Ingredient (\%) & Starter & Grower & Finisher \\
\hline Wheat & 53.511 & 65.490 & 67.949 \\
\hline Soya bean meal & 29.149 & 25.267 & 22.554 \\
\hline Soya oil & 6.969 & 5.177 & 5.819 \\
\hline Wheat bran & 5.000 & & \\
\hline Potato protein & 1.459 & 1.334 & 1.400 \\
\hline Ca-carbonate fine & 1.206 & 0.566 & 0.455 \\
\hline Monocalcium phosphate & 1.072 & 0.553 & 0.261 \\
\hline Vit-min premix without $\mathrm{Zn}$ and $\mathrm{Cu}^{1}$ & 0.500 & 0.500 & 0.500 \\
\hline Na Bicarbonate & 0.256 & 0.221 & 0.210 \\
\hline DL-methionine & 0.249 & 0.230 & 0.213 \\
\hline L-Lysine HCL & 0.224 & 0.240 & 0.215 \\
\hline Salt (NaCl) & 0.166 & 0.166 & 0.174 \\
\hline Xylanase & 0.100 & 0.100 & 0.100 \\
\hline Phytase & 0.100 & 0.100 & 0.100 \\
\hline L-Threonine & 0.038 & 0.056 & 0.051 \\
\hline Calculated AME broilers (Kcal) & 2850 & 2925 & 3000 \\
\hline \multicolumn{4}{|l|}{ Analysed nutrients } \\
\hline Crude protein $\mathrm{g} / 100 \mathrm{~g}$ & 21.5 & 19.6 & 18.9 \\
\hline Crude ash $\mathrm{g} / 100 \mathrm{~g}$ & 5.0 & 3.8 & 3.5 \\
\hline Crude fiber $\mathrm{g} / 100 \mathrm{~g}$ & 2.8 & 2.7 & 2.6 \\
\hline Moisture $\mathrm{g} / 100 \mathrm{~g}$ & 8.4 & 8.8 & 8.7 \\
\hline Ca g/100g & 0.90 & 0.58 & 0.48 \\
\hline$P g / 100 g$ & 0.61 & 0.46 & 0.38 \\
\hline
\end{tabular}

${ }^{1}$ Provided per $\mathrm{kg}$ of final feed: $0.65 \mathrm{~g}$ calcium, $90 \mathrm{mg}$ manganese oxide, $1 \mathrm{mg}$ potassium iodide, $0.25 \mathrm{mg}$ selenium (sodium selenite), $65 \mathrm{mg}$ iron (ferrous carbonate), $10000 \mathrm{UI}$ vitamin A, 2500 Ul vitamin D3, 50 UI vitamin E (all-rac-a-tocopherolacetate), 2 mg vitamin K3, 2 mg vitamin B1, 6 mg vitamin B2, 4 mg vitamin B6 (pyridoxine hydroxychloride), 25 mcg vitamin B12, $40 \mathrm{mg}$ niacinamide, $10 \mathrm{mg}$ calcium D-pantothenate, $10 \mathrm{mg}$ pantothenic acid, $1 \mathrm{mg}$ folic acid, $150 \mathrm{mcg}$ biotin, $300 \mathrm{mg}$ choline chloride, $0.61 \mathrm{~g}$ sepiolite, $0.75 \mathrm{mg}$ butylated hydroxyanisole (BHA), $8.25 \mathrm{mg}$ butylated hydroxytoluene (BHT), 1.20 mg ethoxyquin.

Table 2. Analysed copper and zinc levels in the experimental diets (hydroxychloride trace minerals, HTM and sulphate trace minerals, STM) in high and low dosage. 


\begin{tabular}{|lll|}
\hline Diet & $\begin{array}{l}\text { Copper } \\
\text { Mg/kg }\end{array}$ & $\begin{array}{l}\text { Zinc } \\
\text { Mg/kg }\end{array}$ \\
\hline Starter phase 1 & & \\
\hline STM high & 23 & 116 \\
\hline STM low & 20 & 60 \\
\hline HTM high & 24 & 120 \\
\hline HTM low & 22 & 60 \\
\hline Grower phase 2 & & \\
\hline STM high & 22 & 114 \\
\hline STM low & 22 & 56 \\
\hline HTM high & 22 & 118 \\
\hline HTM low & 21 & 54 \\
\hline Finisher phase 3 & & \\
\hline STM high & 21 & 112 \\
\hline STM low & 22 & 52 \\
\hline HTM high & 22 & 117 \\
\hline HTM low & 22 & 52 \\
\hline
\end{tabular}

Table 3. Body weight (BW), average daily gain (ADG), average daily feed intake (ADFI) and feed conversion ratio (FCR) of the birds fed with the experimental diets (hydroxychloride trace minerals, HTM and sulphate trace minerals, STM) in high and low dosages ( \pm standard error). 


\begin{tabular}{|c|c|c|c|c|c|c|c|c|}
\hline & & STM & & HTM & & P-value & & \\
\hline & Day & High & Low & High & Low & source & level & source*level \\
\hline \multirow[t]{4}{*}{ BW (g) } & 0 & $43.2 \pm 0.2$ & $43.2 \pm 0.1$ & $43.5 \pm 0.3$ & $43.2 \pm 0.2$ & 0.3240 & 0.3747 & 0.4937 \\
\hline & 10 & $275.7 \pm 4.1$ & $278.2 \pm 2.0$ & $277.6 \pm 3.0$ & $279.1 \pm 2.0$ & 0.5471 & 0.3927 & 0.7652 \\
\hline & 27 & $1774.0 \pm 12.7$ & $1787.4 \pm 12.2$ & $1810.2 \pm 168$ & $1806.1 \pm 9.9$ & $\underline{0.0229}$ & 0.6872 & 0.1112 \\
\hline & 34 & $2463.7 \pm 13.5$ & $2476.0 \pm 15.3$ & $2506.9 \pm 21.6$ & $2493.1 \pm 18.3$ & 0.0542 & 0.9657 & 0.2137 \\
\hline \multirow[t]{4}{*}{$\begin{array}{l}\text { ADG } \\
\text { (g/bird/day) }\end{array}$} & $\begin{array}{l}0- \\
10\end{array}$ & $23.3 \pm 0.4$ & $23.5 \pm 0.2$ & $23.4 \pm 0.3$ & $23.6 \pm 0.2$ & 0.6950 & 0.4004 & 0.8352 \\
\hline & $\begin{array}{l}10- \\
27\end{array}$ & $88.2 \pm 0.6$ & $88.8 \pm 0.6$ & $90.2 \pm 0.8$ & $89.8 \pm 0.5$ & 0.0738 & 0.8970 & 0.3155 \\
\hline & $\begin{array}{l}27- \\
34\end{array}$ & $98.7 \pm 0.8$ & $98.3 \pm 0.9$ & $99.5 \pm 1.2$ & $98.2 \pm 1.4$ & 0.7133 & 0.4015 & 0.7773 \\
\hline & $\begin{array}{l}0- \\
34\end{array}$ & $71.0 \pm 0.4$ & $71.6 \pm 0.5$ & $72.5 \pm 0.6$ & $72.2 \pm 0.5$ & $\underline{0.0130}$ & 0.7071 & 0.3407 \\
\hline \multirow[t]{4}{*}{$\begin{array}{l}\text { ADFI } \\
\text { (g/bird/day) }\end{array}$} & $\begin{array}{l}0- \\
10\end{array}$ & $25.1 \pm 0.4$ & $25.2 \pm 0.3$ & $25.1 \pm 0.4$ & $25.4 \pm 0.3$ & 0.6246 & 0.4419 & 0.7749 \\
\hline & $\begin{array}{l}10- \\
27\end{array}$ & $121.2 \pm 0.8$ & $122.0 \pm 0.9$ & $123.4 \pm 1.2$ & $123.8 \pm 1.0$ & 0.0846 & 0.6205 & 0.3499 \\
\hline & $\begin{array}{l}27- \\
34\end{array}$ & $156.8 \pm 1.8$ & $157.0 \pm 1.1$ & $158.3 \pm 1.0$ & $156.0 \pm 1.7$ & 0.8866 & 0.4835 & 0.7457 \\
\hline & $\begin{array}{l}0- \\
34\end{array}$ & $99.8 \pm 0.6$ & $100.6 \pm 0.6$ & $101.5 \pm 0.8$ & $101.5 \pm 0.7$ & $\underline{0.0125}$ & 0.4312 & 0.4505 \\
\hline \multirow[t]{4}{*}{ FCR } & $\begin{array}{l}0- \\
10\end{array}$ & $1.088 \pm 0.007$ & $1.071 \pm 0.001$ & $1.073 \pm 0.015$ & $1.078 \pm 0.012$ & 0.7182 & 0.6065 & 0.7631 \\
\hline & $\begin{array}{l}10- \\
27\end{array}$ & $1.374 \pm 0.006$ & $1.374 \pm 0.004$ & $1.369 \pm 0.004$ & $1.378 \pm 0.006$ & 0.9621 & 0.6985 & 0.9611 \\
\hline & $\begin{array}{l}27- \\
34\end{array}$ & $1.590 \pm 0.020$ & $1.597 \pm 0.010$ & $1.593 \pm 0.016$ & $1.591 \pm 0.026$ & 0.8683 & 0.8420 & 0.9797 \\
\hline & $\begin{array}{l}0- \\
34\end{array}$ & $1.406 \pm 0.008$ & $1.406 \pm 0.034$ & $1.402 \pm 0.005$ & $1.407 \pm 0.008$ & 0.7415 & 0.6981 & 0.6875 \\
\hline
\end{tabular}

Table 4 Carcass yield and breast meat yield of the birds fed with the experimental diets (hydroxychloride trace minerals, HTM and sulphate trace minerals, STM) in high and low dosages.

\begin{tabular}{|llllllll|}
\hline & STM & \multicolumn{3}{c|}{ HTM } & \multicolumn{5}{c|}{ P-value } \\
& High & Low & High & Low & Source & Level & Source*Level \\
\hline Carcass yield & 66.8 & 66.5 & 67.2 & 66.9 & 0.1239 & 0.1956 & 0.8997 \\
(\% of body weight) & \pm 0.19 & \pm 0.22 & \pm 0.22 & \pm 0.29 & & & \\
Breast meat yield & 27.8 & 27.3 & 28.1 & 27.4 & 0.3906 & $\underline{\mathbf{0 . 0 1 7 1}}$ & 0.5172 \\
(\% of carcass weight) & \pm 0.21 & \pm 0.23 & \pm 0.23 & \pm 0.26 & & & \\
\hline
\end{tabular}


Table 5 Mineral contents in ileal and cecal digesta at day 34 of the birds fed with the experimental diets (hydroxychloride trace minerals, HTM and sulphate trace minerals, STM) in high and low dosages.

\begin{tabular}{|c|c|c|c|c|c|c|c|}
\hline & \multicolumn{2}{|l|}{ STM } & \multicolumn{2}{|l|}{ HTM } & \multicolumn{3}{|l|}{ P-value } \\
\hline & High & Low & High & Low & Source & Level & Source*Level \\
\hline \multicolumn{8}{|c|}{ Ileum } \\
\hline \multirow[t]{2}{*}{$\mathrm{Cu}$} & 11.0 & 10.4 & 13.0 & 12.8 & $\underline{0.0040}$ & 0.5539 & 0.7942 \\
\hline & \pm 0.97 & \pm 0.66 & \pm 0.99 & \pm 0.52 & & & \\
\hline \multirow[t]{2}{*}{$\mathrm{Zn}$} & 52.3 & 24.2 & 59.2 & 26.8 & 0.2020 & $\leq 0.0001$ & 0.5616 \\
\hline & \pm 5.60 & \pm 2.23 & \pm 6.67 & \pm 1.48 & & & \\
\hline \multicolumn{8}{|c|}{ Cecum } \\
\hline \multirow[t]{2}{*}{$\mathrm{Cu}$} & 89.9 & 96.1 & 89.2 & 92.0 & 0.8163 & 0.6569 & 0.8671 \\
\hline & \pm 11.42 & \pm 10.34 & \pm 5.45 & \pm 15.59 & & & \\
\hline \multirow[t]{2}{*}{$\mathrm{Zn}$} & $175.7^{\mathrm{ab}}$ & $117.7^{\mathrm{bc}}$ & $224.8^{a}$ & $102.4^{\mathrm{C}}$ & 0.2896 & $\leq 0.0001$ & $\underline{0.0472}$ \\
\hline & \pm 24.66 & \pm 14.16 & \pm 21.97 & \pm 21.71 & & & \\
\hline
\end{tabular}

Table 6. Alpha diversity parameters in the ileum and cecum $(n=12)$ at day 34 of the birds fed with the experimental diets (hydroxychloride trace minerals, HTM and sulphate trace minerals, STM) in high and low dosages.

\begin{tabular}{|c|c|c|c|c|c|c|}
\hline Region & Source & Level & observed_otus & shannon & evenness & faith_pd \\
\hline \multirow[t]{4}{*}{ Ileum } & \multirow[t]{2}{*}{ STM } & High & $43 \pm 10^{\mathrm{ab}}$ & $2.6 \pm 0.6$ & $0.48 \pm 0.09$ & $4.0 \pm 0.8^{\mathrm{ab}}$ \\
\hline & & Low & $44 \pm 9^{a b}$ & $2.3 \pm 0.6$ & $0.43 \pm 0.13$ & $4.1 \pm 1.2^{\mathrm{ab}}$ \\
\hline & \multirow[t]{2}{*}{ HTM } & High & $50 \pm 14^{\mathrm{a}}$ & $2.8 \pm 0.6$ & $0.50 \pm 0.11$ & $4.4 \pm 0.9^{a}$ \\
\hline & & Low & $39 \pm 8^{b}$ & $2.5 \pm 0.5$ & $0.48 \pm 0.09$ & $3.6 \pm 0.7^{b}$ \\
\hline \multirow{2}{*}{\multicolumn{2}{|c|}{ P-value main effects }} & Source & 0.8602 & 0.3557 & 0.4680 & 0.7085 \\
\hline & & Level & 0.1133 & 0.1440 & 0.4100 & 0.1112 \\
\hline \multirow[t]{4}{*}{ Cecum } & \multirow[t]{2}{*}{ STM } & High & $288 \pm 62$ & $5.6 \pm 0.4^{b}$ & $0.69 \pm 0.03$ & $18 \pm 2^{b}$ \\
\hline & & Low & $308 \pm 67$ & $5.8 \pm 0.4^{a b}$ & $0.70 \pm 0.03$ & $19 \pm 2^{a b}$ \\
\hline & \multirow[t]{2}{*}{ HTM } & High & $312 \pm 41$ & $5.9 \pm 0.3^{a b}$ & $0.71 \pm 0.03$ & $19 \pm 1^{a b}$ \\
\hline & & Low & $327 \pm 29$ & $6.0 \pm 0.2^{\mathrm{a}}$ & $0.71 \pm 0.02$ & $20 \pm 1^{a}$ \\
\hline \multirow{2}{*}{\multicolumn{2}{|c|}{ P-value main effects }} & Source & 0.3588 & 0.0665 & 0.0990 & 0.3025 \\
\hline & & Level & 0.1270 & 0.3325 & 0.7887 & 0.0696 \\
\hline
\end{tabular}

*Superscripts inside of each column represents significant differences among treatments per region based on pairwise comparisons $(P<0.05)$. 
Table 7. Genus composition of the ileum at day $35(n=12)$ at day 34 of the birds fed with the experimental diets (hydroxychloride trace minerals, HTM and sulphate trace minerals, STM) in high (80 ppm) and low (20 ppm) dosages.

\begin{tabular}{|c|c|c|c|c|}
\hline & STM & & HTM & \\
\hline & High & Low & High & Low \\
\hline Lactobacillus & $92.2 \pm 9.5^{\mathrm{ab}}$ & $98.0 \pm 3.8^{a}$ & $88.8 \pm 11.08^{b}$ & $96.2 \pm 7.97^{\mathrm{ab}}$ \\
\hline Enterococcus & $6.10 \pm 8.60^{\mathrm{ab}}$ & $0.852 \pm 2.24^{\mathrm{b}}$ & $7.7 \pm 8.2^{\mathrm{a}}$ & $3.08 \pm 7.29^{a b}$ \\
\hline Streptococcus & $0.743 \pm 0.868^{\mathrm{ab}}$ & $0.429 \pm 1.01^{b}$ & $2.4 \pm 3.5^{\mathrm{a}}$ & $0.385 \pm 0.800^{b}$ \\
\hline Candidatus Arthromitus & $0.647 \pm 1.354$ & $0.316 \pm 0.534$ & $0.113 \pm 0.170$ & $0.288 \pm 0.544$ \\
\hline Corynebacterium 1 & $0.071 \pm 0.084$ & $0.127 \pm 0.133$ & $0.250 \pm 0.342$ & $0.018 \pm 0.016$ \\
\hline Staphylococcus & $0.050 \pm 0.063$ & $0.078 \pm 0.098$ & $0.378 \pm 0.603$ & $0.024 \pm 0.019$ \\
\hline Escherichia-Shigella & $0.073 \pm 0.142$ & $0.033 \pm 0.076$ & $0.197 \pm 0.477$ & $0.015 \pm 0.018$ \\
\hline Weissella & $0.006 \pm 0.010^{\mathrm{ab}}$ & $0.023 \pm 0.045^{\mathrm{ab}}$ & $0.021 \pm 0.030^{a}$ & $0.001 \pm 0.001^{b}$ \\
\hline Bifidobacterium & $0.007 \pm 0.008^{\mathrm{ab}}$ & $0.014 \pm 0.016^{a b}$ & $0.039 \pm 0.053^{a}$ & $0.008 \pm 0.015^{b}$ \\
\hline Brachybacterium & $0.026 \pm 0.065$ & $0.025 \pm 0.042$ & $0.037 \pm 0.080$ & $0.000 \pm 0.000$ \\
\hline Aerococcus & $0.010 \pm 0.033$ & $0.017 \pm 0.034$ & $0.011 \pm 0.017$ & $0.000 \pm 0.000$ \\
\hline Clostridium sensu stricto 1 & $0.018 \pm 0.050$ & $0.004 \pm 0.007$ & $0.018 \pm 0.057$ & $0.004 \pm 0.011$ \\
\hline Blautia & $0.001 \pm 0.001^{\mathrm{ab}}$ & $0.003 \pm 0.006^{a b}$ & $0.007 \pm 0.009^{a}$ & $0.001 \pm 0.002^{b}$ \\
\hline Dietzia & $0.000 \pm 0.001$ & $0.002 \pm 0.004$ & $0.002 \pm 0.004$ & $0.000 \pm 0.000$ \\
\hline Brevibacterium & $0.007 \pm 0.021$ & $0.006 \pm 0.015$ & $0.007 \pm 0.019$ & $0.000 \pm 0.000$ \\
\hline Ruminococcus torques $g$ & $0.001 \pm 0.002^{\mathrm{ab}}$ & $0.003 \pm 0.003^{\mathrm{ab}}$ & $0.004 \pm 0.005^{a}$ & $0.002 \pm 0.006^{b}$ \\
\hline Faecalibacterium & $0.001 \pm 0.001$ & $0.004 \pm 0.006$ & $0.002 \pm 0.003$ & $0.003 \pm 0.009$ \\
\hline Pediococcus & $0.001 \pm 0.001$ & $0.000 \pm 0.000$ & $0.002 \pm 0.004$ & $0.000 \pm 0.002$ \\
\hline Lachnospiraceae_unknown & $0.002 \pm 0.004$ & $0.001 \pm 0.003$ & $0.003 \pm 0.005$ & $0.000 \pm 0.001$ \\
\hline Jeotgalicoccus & $0.006 \pm 0.017$ & $0.008 \pm 0.013$ & $0.009 \pm 0.016$ & $0.000 \pm 0.000$ \\
\hline Facklamia & $0.001 \pm 0.003$ & $0.001 \pm 0.003$ & $0.002 \pm 0.005$ & $0.000 \pm 0.000$ \\
\hline Eubacterium hallii $g$ & $0.000 \pm 0.000^{\mathrm{ab}}$ & $0.000 \pm 0.001^{a b}$ & $0.001 \pm 0.001^{a}$ & $0.000 \pm 0.000^{b}$ \\
\hline Anaerostipes & $0.000 \pm 0.000$ & $0.000 \pm 0.000$ & $0.000 \pm 0.000$ & $0.000 \pm 0.001$ \\
\hline CAG-56 & $0.000 \pm 0.000$ & $0.000 \pm 0.000$ & $0.000 \pm 0.001$ & $0.000 \pm 0.001$ \\
\hline Sellimonas & $0.000 \pm 0.001$ & $0.000 \pm 0.001$ & $0.001 \pm 0.002$ & $0.000 \pm 0.002$ \\
\hline Saccharimonadales_unknown & $0.000 \pm 0.001$ & $0.001 \pm 0.002$ & $0.000 \pm 0.000$ & $0.000 \pm 0.000$ \\
\hline Paracoccus & $0.000 \pm 0.000$ & $0.000 \pm 0.001$ & $0.000 \pm 0.000$ & $0.000 \pm 0.000$ \\
\hline
\end{tabular}

*Superscripts inside of each row represents significant differences among treatments $(P<0.05)$. 
Table 8. Genera composition of the cecum higher than $1 \%$ relative abundance and genera presenting significant differences at day $34(n=12)$ of the birds fed with the experimental diets (hydroxychloride trace minerals, HTM and sulphate trace minerals, STM) in high (80 ppm) and low (20 ppm) dosages. 


\begin{tabular}{|c|c|c|c|c|}
\hline & STM & & HTM & \\
\hline & High & Low & High & Low \\
\hline Lactobacillus & $17.6 \pm 5.70$ & $17.1 \pm 8.50$ & $17.9 \pm 5.50$ & $14.7 \pm 5.00$ \\
\hline Lachnospiraceae_other & $14.0 \pm 3.30$ & $15.4 \pm 4.40$ & $15.4 \pm 4.60$ & $12.1 \pm 3.40$ \\
\hline Bifidobacterium & $11.5 \pm 6.80$ & $9.20 \pm 7.40$ & $7.90 \pm 4.10$ & $9.90 \pm 5.10$ \\
\hline Faecalibacterium & $10.0 \pm 6.70$ & $12.7 \pm 6.60$ & $14.1 \pm 5.90$ & $12.3 \pm 4.90$ \\
\hline Ruminococcus torques g & $8.40 \pm 5.40$ & $6.60 \pm 2.90$ & $7.20 \pm 3.50$ & $8.50 \pm 5.20$ \\
\hline Blautia & $6.30 \pm 3.30^{\mathrm{ab}}$ & $6.30 \pm 4.30^{\mathrm{ab}}$ & $4.70 \pm 1.40^{\mathrm{b}}$ & $7.70 \pm 3.10^{\mathrm{a}}$ \\
\hline Ruminococcaceae_other & $4.50 \pm 1.70$ & $3.70 \pm 1.00$ & $4.20 \pm 1.40$ & $4.50 \pm 1.40$ \\
\hline Ruminococcaceae UCG-014 & $3.70 \pm 2.60$ & $4.10 \pm 3.20$ & $4.70 \pm 1.40$ & $3.80 \pm 1.80$ \\
\hline Butyricicoccus & $2.90 \pm 1.80$ & $3.50 \pm 2.20$ & $3.50 \pm 2.40$ & $3.40 \pm 1.40$ \\
\hline Alistipes & $2.90 \pm 2.00$ & $3.10 \pm 2.20$ & $2.70 \pm 2.20$ & $2.70 \pm 1.90$ \\
\hline Ruminiclostridium 5 & $2.50 \pm 1.80^{\mathrm{ab}}$ & $0.900 \pm 0.500^{b}$ & $1.90 \pm 1.50^{\mathrm{ab}}$ & $2.20 \pm 1.10^{\mathrm{a}}$ \\
\hline Anaerostipes & $1.80 \pm 2.00^{\mathrm{ab}}$ & $2.00 \pm 1.30^{\mathrm{ab}}$ & $1.10 \pm 0.500^{\mathrm{b}}$ & $2.20 \pm 1.20^{\mathrm{a}}$ \\
\hline Sellimonas & $1.50 \pm 1.10$ & $1.10 \pm 0.400$ & $1.00 \pm 0.500$ & $1.50 \pm 0.600$ \\
\hline Eubacterium halliig & $1.40 \pm 1.10$ & $1.90 \pm 1.30$ & $1.10 \pm 0.700$ & $1.50 \pm 0.900$ \\
\hline Dorea & $1.30 \pm 1.60$ & $1.20 \pm 1.30$ & $1.60 \pm 1.70$ & $2.10 \pm 1.70$ \\
\hline Clostridiales_other & $1.00 \pm 0.700$ & $1.10 \pm 0.900$ & $1.00 \pm 0.500$ & $1.50 \pm 0.800$ \\
\hline Eubacterium coprostanoligenes & $0.930 \pm 0.570$ & $1.20 \pm 0.700$ & $0.750 \pm 0.470$ & $0.940 \pm 0.590$ \\
\hline Subdoligranulum & $0.900 \pm 0.790$ & $1.20 \pm 1.20$ & $1.50 \pm 1.00$ & $0.990 \pm 0.620$ \\
\hline Firmicutes_other & $0.790 \pm 0.680$ & $1.00 \pm 1.00$ & $1.10 \pm 1.20$ & $0.540 \pm 0.550$ \\
\hline Christensenellaceae R-7 g & $0.210 \pm 0.250^{b}$ & $0.280 \pm 0.250^{b}$ & $0.220 \pm 0.320^{\mathrm{b}}$ & $0.630 \pm 0.470^{a}$ \\
\hline Streptococcus & $0.160 \pm 0.230^{\mathrm{b}}$ & $0.380 \pm 0.570^{\mathrm{ab}}$ & $0.870 \pm 1.280^{\mathrm{a}}$ & $0.500 \pm 0.720^{a b}$ \\
\hline Ruminococcus 1 & $0.200 \pm 0.340^{\mathrm{ab}}$ & $0.170 \pm 0.300^{\mathrm{ab}}$ & $0.110 \pm 0.170^{\mathrm{b}}$ & $0.270 \pm 0.260^{\mathrm{a}}$ \\
\hline Ruminococcaceae UCG-004 & $0.180 \pm 0.100^{\mathrm{ab}}$ & $0.180 \pm 0.120^{\mathrm{ab}}$ & $0.160 \pm 0.090^{\mathrm{b}}$ & $0.260 \pm 0.070^{a}$ \\
\hline CHKCIOO2 & $0.210 \pm 0.080^{a}$ & $0.130 \pm 0.110^{b}$ & $0.130 \pm 0.060^{\mathrm{b}}$ & $0.160 \pm 0.060^{\mathrm{ab}}$ \\
\hline Tyzzerella & $0.140 \pm 0.160^{\mathrm{ab}}$ & $0.090 \pm 0.120^{b}$ & $0.060 \pm 0.060^{\mathrm{b}}$ & $0.180 \pm 0.100^{a}$ \\
\hline vadinBB60_uncultured & $0.030 \pm 0.040^{\mathrm{b}}$ & $0.190 \pm 0.480^{\mathrm{ab}}$ & $0.060 \pm 0.060^{\mathrm{a}}$ & $0.060 \pm 0.100^{\mathrm{ab}}$ \\
\hline Anaerotruncus & $0.030 \pm 0.030^{\mathrm{ab}}$ & $0.060 \pm 0.050^{a}$ & $0.020 \pm 0.010^{b}$ & $0.030 \pm 0.060^{a b}$ \\
\hline Tyzzerella 3 & $0.010 \pm 0.010^{\mathrm{b}}$ & $0.030 \pm 0.020^{\mathrm{a}}$ & $0.020 \pm 0.010^{\mathrm{ab}}$ & $0.020 \pm 0.010^{\mathrm{ab}}$ \\
\hline Eubacterium nodatum g & $0.010 \pm 0.010^{\mathrm{ab}}$ & $0.020 \pm 0.020^{\mathrm{ab}}$ & $0.010 \pm 0.010^{\mathrm{b}}$ & $0.020 \pm 0.010^{a}$ \\
\hline Ruminococcaceae_uncultured & $0.010 \pm 0.014^{\mathrm{ab}}$ & $0.004 \pm 0.006^{\mathrm{ab}}$ & $0.001 \pm 0.001^{\mathrm{b}}$ & $0.006 \pm 0.006^{\mathrm{a}}$ \\
\hline
\end{tabular}




\begin{tabular}{|lllll|}
\hline Family XIII AD3011 g & $0.009 \pm 0.008^{\mathrm{ab}}$ & $0.009 \pm 0.006^{\mathrm{ab}}$ & $0.009 \pm 0.008^{\mathrm{b}}$ & $0.022 \pm 0.008^{\mathrm{a}}$ \\
\hline Eubacterium brachyg & $0.007 \pm 0.011^{\mathrm{b}}$ & $0.015 \pm 0.023^{\mathrm{ab}}$ & $0.010 \pm 0.017^{\mathrm{b}}$ & $0.032 \pm 0.018^{\mathrm{a}}$ \\
\hline vadinBB60_other & $0.006 \pm 0.015^{\mathrm{b}}$ & $0.009 \pm 0.018^{\mathrm{b}}$ & $0.031 \pm 0.020^{\mathrm{a}}$ & $0.004 \pm 0.005^{\mathrm{b}}$ \\
\hline Pygmaiobacter & $0.006 \pm 0.014^{\mathrm{b}}$ & $0.007 \pm 0.009^{\mathrm{ab}}$ & $0.005 \pm 0.009^{\mathrm{b}}$ & $0.074 \pm 0.150^{\mathrm{a}}$ \\
\hline Family XIII UCG-001 g & $0.004 \pm 0.007^{\mathrm{b}}$ & $0.014 \pm 0.011^{\mathrm{a}}$ & $0.006 \pm 0.007^{\mathrm{b}}$ & $0.017 \pm 0.009^{\mathrm{a}}$ \\
\hline vadinBB60_uncultured Firm. & $0.004 \pm 0.008^{\mathrm{ab}}$ & $0.008 \pm 0.018^{\mathrm{ab}}$ & $0.014 \pm 0.012^{\mathrm{a}}$ & $0.004 \pm 0.007^{\mathrm{b}}$ \\
\hline Brachybacterium & $0.003 \pm 0.012^{\mathrm{ab}}$ & $0.004 \pm 0.011^{\mathrm{a}}$ & $0.001 \pm 0.003^{\mathrm{ab}}$ & $0.000 \pm 0.000^{\mathrm{b}}$ \\
\hline Peptococcaceae_other & $0.001 \pm 0.001^{\mathrm{ab}}$ & $0.002 \pm 0.006^{\mathrm{ab}}$ & $0.000 \pm 0.001$ & $0.002 \pm 0.003^{\mathrm{a}}$ \\
\hline
\end{tabular}

*Superscripts inside of each row represents significant differences among treatments $(P<0.05)$.

\section{Figures}
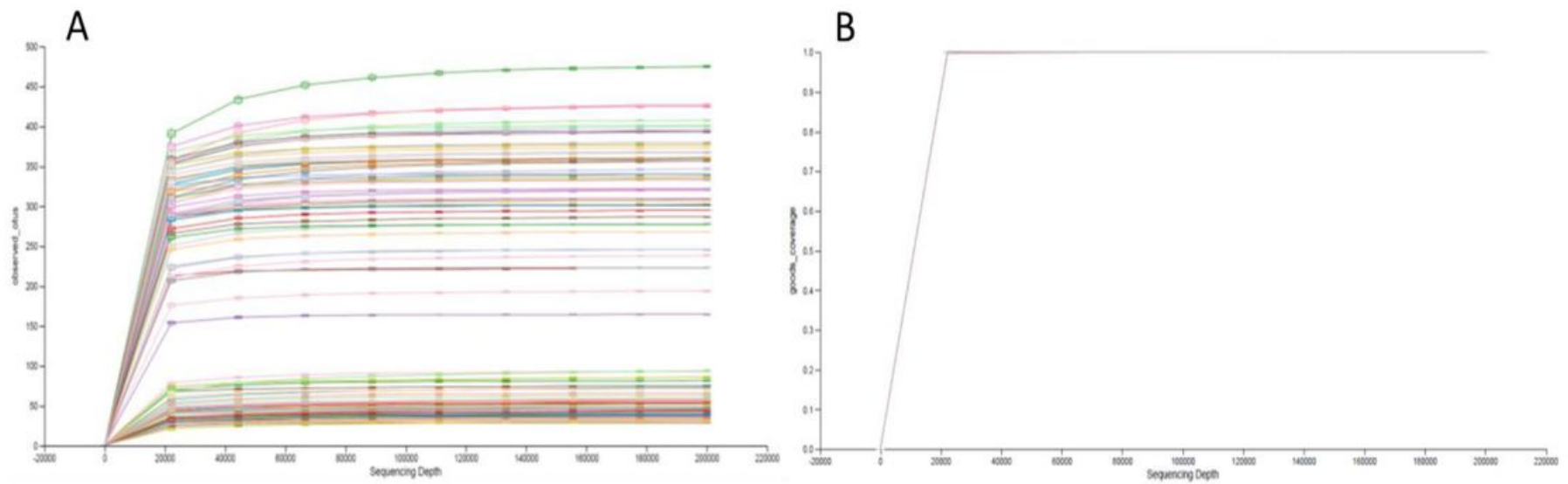

\section{Figure 1}

Alpha rarefaction of observed OTUs (A) and good coverages (B) in all the samples at day 34 . 


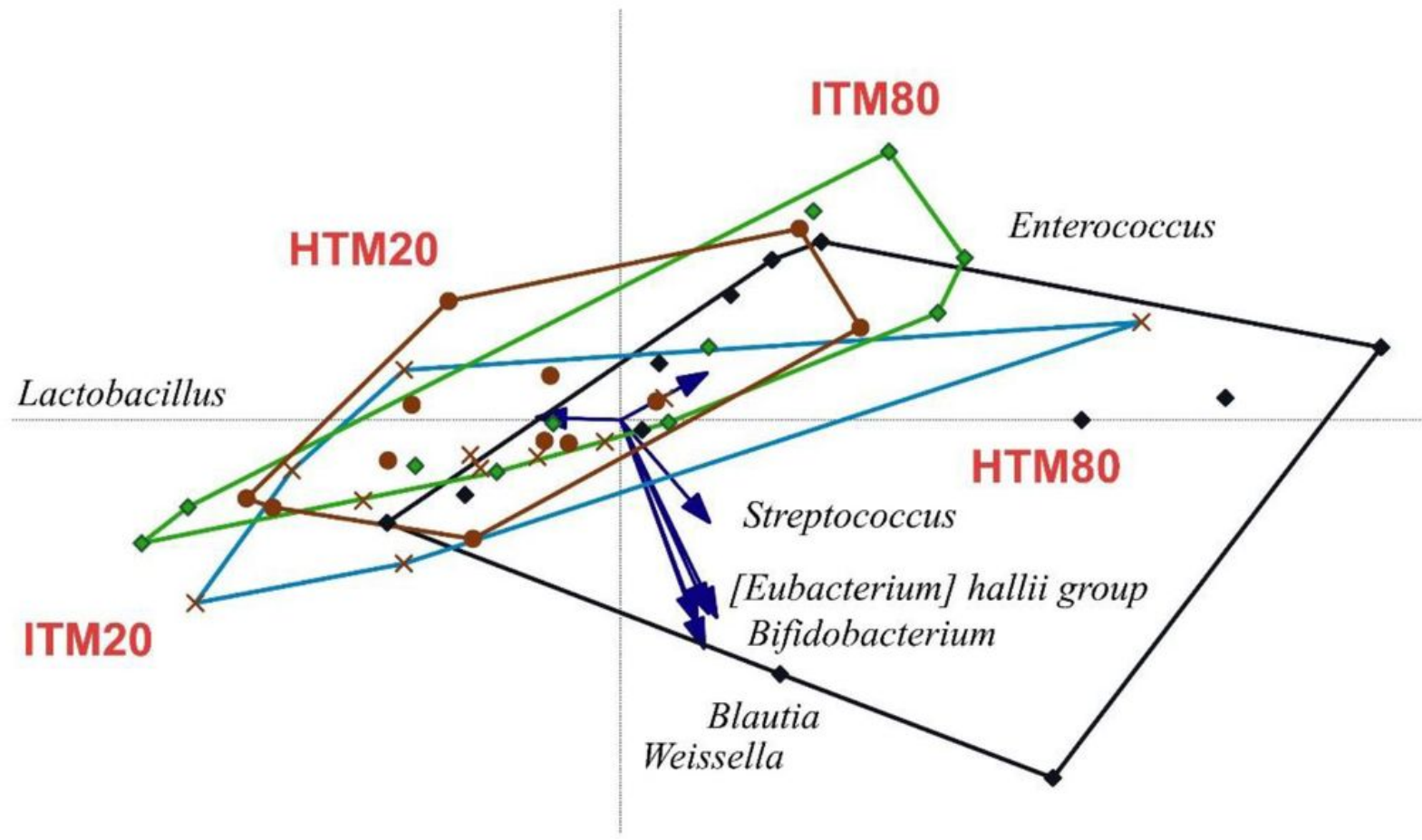

Figure 2

Redundancy analysis (RDA) of the ileum at day 34. Significant differences are represented by the arrows. HTM20: 20 ppm Zn from hydroxychloride trace minerals (HTM), HTM80: 80 ppm Zn from HTM, ITM20: 20 ppm Zn from sulphate trace minerals (STM), ITM80: 80 ppm Zn from STM. 


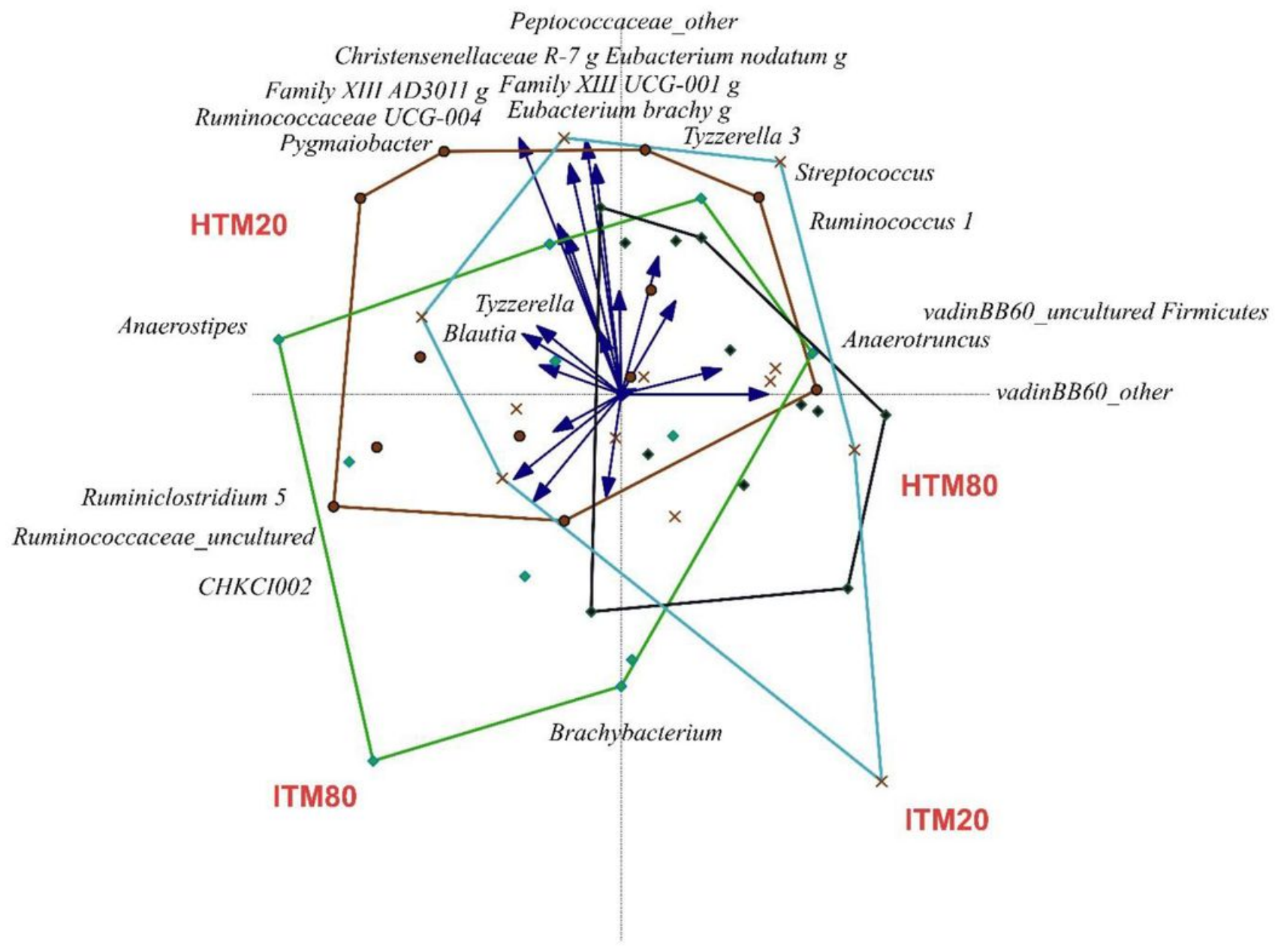

Figure 3

Redundancy analysis (RDA) of the cecum at day 34. Significant differences are represented by the arrows. HTM20: 20 ppm Zn from hydroxychloride trace minerals (HTM), HTM80: 80 ppm Zn from HTM, ITM20: 20 ppm Zn from sulphate trace minerals (STM), ITM80: 80 ppm Zn from STM. 